\title{
VIOLÊNCIA CONTRA A MULHER: UMA RELAÇÃO ENTRE DIMENSÕES SUBJETIVAS E A PRODUÇÃO DE INFORMAÇÃO
}

VIOLENCE AGAINST WOMEN: A RELATION BETWEEN SUBJECTIVE DIMENSIONS AND THE PRODUCTION OF INFORMATION

VIOLENCIA CONTRA LA MUJER: LA RELACIÓN ENTRE LAS DIMENSIONES SUBJETIVAS Y LA PRODUCCIÓN DE INFORMACIÓN

${ }^{1}$ Mariana de Lima Campos, ${ }^{1}$ Gustavo Henrique Moreira Dias Almeida

${ }^{1}$ Fundação João Pinheiro

\section{Correspondência}

${ }^{1}$ Mariana de Lima Campos

Fundação João Pinheiro

Belo Horizonte, MG

Email: marianalcampos@gmail.com

ORCID: http://orcid.org/0000-0001-9505-

$\underline{6426}$

Submetido em: 19-05-2016

Aceito em: 29-12-2016

Publicado: 11-04-2017

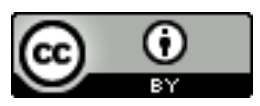

JITA: BG. Information dissemination and diffusion 
RESUMO: A violência contra a mulher é considerada uma questão social e atinge a vida de milhões de mulheres em seus diferentes espaços de atuação. Um importante mecanismo para identificar e diagnosticar incidências relativas a este fenômeno constitui-se nos sistemas de informação e comunicação do setor público, pois não só permitem o mapeamento de casos, como a construção de indicadores e certo dimensionamento do problema, possibilitando, portanto, a construção de iniciativas mais eficazes relacionadas ao seu enfrentamento. O ponto aqui a ser ressaltado versa sobre a informação produzida e inserida nestes sistemas, atentando-se sobre a influência de dimensões subjetivas derivadas de valores, crenças, significados e sentidos atribuídos à violência contra a mulher. Por meio de uma revisão bibliográfica e documental sobre o tema, a análise refere-se à inserção de dados no Sistema de Informações de Agravos de Notificação (SINAN), do Ministério da Saúde. Infere-se que valores arraigados e instituídos culturalmente na sociedade refletem na informação produzida e em maior nível, na existência de subnotificações, constituindo-se como um dos aspectos negativos em relação à inserção de dados no sistema e ao enfrentamento da violência contra as mulheres.Compreende-se que tais fatos remetem a uma visão histórica e cultural marcada por concepções valorativas em relação aos padrões hierárquicos de gênero impactando nos procedimentos de alimentação dos sistemas e no compromisso dos profissionais com os propósitos estabelecidos pelos serviços prestados.

PALAVRAS-CHAVE: Violência contra a mulher. SINAN. Dimensões subjetivas. Produção de informação. Subnotificação.

ABSTRACT: The violence against women is considered a social issue and affects the lives of millions of women in their different areas of acting. An important mechanism to identify and diagnose incidents related to this phenomenon are the information and communication systems in the public sector because allow the mapping of cases, the construction of indicators and an idea of the magnitude of the problem, allowing therefore, building more effective initiatives related to its combat. The point to be emphasized is about data produced and inserted in these systems, keeping in mind the influence of subjective dimensions derived values, beliefs, meanings and meanings attributed to violence against women. Through a literature review and documentary on the subject, the analysis refers to the inclusion of data in the Sistema de Informações de Agravos de Notificação (SINAN), the Ministry of Health. It is believed that values established culturally in society are reflected in the information produced and higher level, the existence of underreporting, establishing itself as one of the negative aspects related to data entry into the system and to combat with violence against women. It is understood that these facts refer to a historical and cultural vision marked by evaluative concepts regarding hierarchical gender patterns impacting on the procedures of the systems and commitment of professionals with the purposes established for their services.

KEYWORDS: Violence against women. SINAN. Subjective dimensions. Production of information. Underreporting.

RESUMEN: La violencia contra la mujer se considera un problema social. Un mecanismo importante para identificar y diagnosticar los incidentes relacionados con este fenómeno son los sistemas de información y de comunicación en del sector público que no sólo permitirá tener uma visión de los casos, tales como la construcción de indicadores y cierto dimensionamiento del problema, lo que permite la construcción de iniciativas más eficaces en relación con la lucha contra lo. El punto a destacar es acerca de las informaciones producidas y se incorporadas en estos sistemas, teniendo en cuenta la influencia de las dimensiones subjetivas resultantes de valores, creencias, significados y significados atribuidos a la violencia contra las mujeres. A través de una revisión bibliográfica y documental sobre el tema, el análisis se refiere a la inserción de los datos en el Sistema de Informações de Agravos de Notificação (SINAN), de el Ministerio de Salud. Se entiende que los valores y estableció culturalmente en la sociedad se reflejan en los datos presentados y el nivel más alto, la existencia de subregistro, estableciéndose como uno de los aspectos negativos relacionados con la entrada de datos en el sistema y para hacer frente a la violencia contra la mujer. Se entiende que esto se refiere a una visión histórica y cultural marcado por conceptos de evaluación con respecto a los patrones de jerárquicas de gênero que reflejan los procedimientos de los sistemas y el compromiso de los profesionales con los propósitos establecidos por sus servicios.

PAlaVRaS-ClaVE: Violencia contra la mujer. SINAN. Dimensiones subjetivas. Producción de información. Subregistro. 


\section{INTRODUÇÃ̃o}

Sob a perspectiva da Gestão Pública, a importância da gestão da informação dentro das organizações públicas vem crescendo cada vez mais diante do cenário complexo que envolve constantes demandas que se desdobram dos anseios da sociedade. Sua contribuição está inserida no desenvolvimento de instrumentos de gestão das rotinas organizacionais somadas ao tratamento de dados brutos para o uso estratégico da informação pelo poder público em várias áreas sociais de atuação, colaborando para dar sentido às mudanças no ambiente externo à organização (CHOO, 2003). Nesse contexto, o uso de sistemas de informação permite que dados possam ser armazenados e processados e que as informações possam ser disponibilizadas de modo a torná-las acessíveis e úteis não apenas à administração pública e seus processos organizacionais, mas também adequadas e voltadas à sociedade de uma forma geral.

O horizonte analítico deste trabalho está atrelado a uma reflexão que perpassa por estes sistemas voltando-se, entretanto, ao âmbito da produção de informações, considerando as dimensões subjetivas e as percepções dos agentes públicos nesses processos, tendo em vista que a atuação destes mesmos agentes não se limita apenas a uma questão técnica, mas se configura também enquanto uma prática social relevante.

Dentre os diferentes sistemas de informações existentes, a análise se volta ao Sistema de Notificação Compulsória dos Casos de Violência contra a Mulher no âmbito do Sistema de Informação de Agravos de Notificação do Ministério da Saúde (SINAN). Busca-se direcionar o enfoque para dimensões outras que perpassam por aspectos referentes à obtenção de dados e à produção das informações sobre a violência contra as mulheres. Como recurso metodológico adotou-se uma revisão bibliográfica e documental relacionada ao tema.

Nosso objetivo é destacar, no âmbito da produção de informação sobre a violência contra as mulheres, a relevância das dimensões subjetivas dos agentes responsáveis por tal ação, estabelecendo uma reflexão sobre os aspectos culturais da violência de gênero, seus impactos na elaboração das fichas de notificação de agravos e, consequentemente, na fiabilidade da informação produzida. Esta perspectiva ganha relevância dado que a violência contra a mulher vem cada vez mais deixando de ser tratada como um problema marginal pelo Estado e sociedade civil organizada, mas também passa progressivamente a ser alvo de questionamentos e demandas de diferentes setores e atores ao constar na agenda pública.

Tal inquietação torna-se instigante na medida em que existem estudos empíricos que demonstram a ocorrência de subnotificações por parte dos profissionais da área de saúde responsáveis pelo atendimento de mulheres em situação de violência -, somadas ao baixo número de casos notificados de forma geral em muitos municípios visualizados no SINAN, se comparados à proporção do fenômeno na sociedade atualmente. 
Desta forma, infere-se que estes profissionais, de uma maneira geral, reproduzem conceitos e vivências imbricadas na própria cultura, socialmente construída e marcada por diversas formas de expressão da desigualdade de gênero. Esse contexto reflete a percepção e o sentido que os indivíduos atribuem à violência contra as mulheres na sociedade, impactando na informação produzida. Assim, o foco de nossa análise recai sobre a atuação dos operacionalizadores dos sistemas informacionais e a forma como a sua percepção e ação podem influenciar na produção de dados e informações importantes não só para o monitoramento de casos de violência contra as mulheres, como para o seu enfrentamento.

Interessante perceber que a produção de informação, neste contexto, guarda relação com a premissa de González de Gómez (2012:43) acerca do conceito de regime de informação, o qual é caracterizado pela autora como o modo de produção informacional dominante em uma formação social que permite a definição de sujeitos, instituições, regras e autoridades informacionais, meios e recursos preferenciais de informação, os padrões e os arranjos organizacionais de seu processamento seletivo e seus dispositivos de preservação e distribuição. O que estaria em voga seria justamente como se definem a geração, circulação, o acesso, as direções, mediações e usos da informação. A percepção da realidade pelos produtores se materializa nas informações produzidas, ou seja, presume-se que a informação esteja imbuída de um viés condicionante da visão de mundo, interesses, critérios de valor, micro relações de poder presentes no contexto social em que os agentes estejam inseridos, que orientam escolhas que conduzem de diferentes maneiras os desenhos dos processos de informação.

Discutir-se-á a peculiaridade das informações produzidas perante a possibilidade de influências de concepções valorativas arraigadas e instituídas na sociedade, que podem ter impacto direto na inserção de dados ao sistema e no compromisso dos profissionais com os propósitos estabelecidos pelos serviços prestados quando relacionadas à violência contra as mulheres.

Nossa reflexão abordará inicialmente a concepção deste tipo específico de violência a partir das discussões relativas à desigualdade de gênero assentadas em relações de poder existentes entre homens e mulheres na sociedade. Ademais é abordada a relação da violência contra a mulher em conjunto com as políticas e as tecnologias de informação e comunicação no âmbito da administração pública e, especificamente, no campo da saúde considerando o Sistema de Informação de Agravos de Notificação do Ministério da Saúde enquanto uma fonte de informação e produção de dados existentes sobre o fenômeno. Por fim, busca-se nas considerações finais, elucidar o papel das dimensões subjetivas na produção de informação referente à violência contra as mulheres, evidenciando os impactos gerados não só na alimentação dos sistemas como também, num âmbito de enfrentamento do fenômeno. 


\section{GÊNERO, DESIGUALDADE E VIOLÊNCIA CONTRA AS MULHERES}

O conceito de gênero foi inserido na produção acadêmica sobre as mulheres nos anos de 1970 (FARAH, 2004). Perpassa pela forma como a sociedade designa a homens e mulheres diferentes papéis, direitos e oportunidades de acordo com seu sexo (SOARES, 2004), os tornando sujeitos a valores socialmente estabelecidos. Desta forma, é um conjunto de construções ou atributos provenientes das relações entre homens e mulheres.

Esses significados, tanto da construção do ser homem quanto do ser mulher instigam reflexões por conterem elementos que marcam as relações de poder em diversas sociedades (HEILBORN et al,2010).

A violência contra a mulher se traduz como a face mais perversa das relações de poder imbuídas na própria definição do conceito de gênero. Este tipo de violência é um fenômeno que atinge todos os espaços de atuação das mulheres, sejam públicos ou privados, constatação esta encontrada na Política Nacional de Enfrentamento à Violência Contra as Mulheres (BRASIL, 2011) que apresenta alguns dados existentes sobre o fenômeno. Enquanto os homens são impactados pela violência praticada predominantemente nos espaços públicos, as mulheres tendem a ser vítimas não só nesses espaços, mas principalmente no âmbito doméstico, onde muitas vezes sofrem constrangimentos e violência praticados por seus companheiros e familiares, advindas das relações pessoais de convívio ou relações íntimas de afeto.

Ainda segundo a perspectiva abordada, este tipo específico de violência carrega a marca distintiva da categoria social de gênero e assume formas diferenciadas, constituindo-se como toda ação ou conduta que cause não apenas o sofrimento ou dano físico à mulher, mas também psicológico, moral, patrimonial, sexual e inclusive danos causados por crime doloso ${ }^{1}$, atos que se constituem como violações de direitos. Interessante observar que tal fenômeno relacionado às formas de violência se faz presente na vida de diferentes mulheres independente de origem, idade, raça, classe social, estado civil, escolaridade ou mesmo orientação sexual. Na medida em que a violência toma outras formas, alguns elementos começam a emergir como forças explicativas para a dificuldade de que seus tipos sejam percebidos para além da violência física. O principal elemento se deve à construção social de valores e comportamentos patriarcais, em que há a naturalização das violências de gênero e que mesmo ocorrendo com muita frequência, é marcada pela invisibilidade, banalização e aceitação cultural (SCHRAIBER et al., 2009).

Estas dificuldades são legitimadas pelo poder masculino hegemônico, ainda fortemente cravado na cultura brasileira, conceituado no âmbito dos estudos feministas como um sistema

\footnotetext{
${ }^{1} \mathrm{O}$ feminicídio é o assassinato de uma mulher pela condição de ser mulher. Constitui-se como a ultima etapa do ciclo da violência contra a mulher cujo impacto é silenciado, precedido por outros eventos como abusos físicos ou psicológicos. O feminicídio foi tipificado recentemente como um agravante do crime de homicídio através da Lei 13.104/2015, sendo considerado a partir de então como um crime hediondo.
} 
de dominação patriarcal. O patriarcado pautado nas desigualdades de gênero é uma estrutura social e um movimento histórico que ordena e naturaliza as relações de poder entre homens e mulheres e, dessa forma, produz e reproduz desigualdades sociais em diferentes espaços, além de perpetuar suas estruturas ao longo do tempo e em diversas sociedades, mesmo que de maneiras diferentes.

De acordo com a Política Nacional de Enfrentamento à Violência Contra as Mulheres (BRASIL, 2011), este tipo específico de violência pode ser considerado a expressão máxima das desigualdades de gênero e o rompimento dessa circunstância se mostra complexa devido a diversos fatores, dentre eles, a falta de percepção da mulher de que está envolvida em uma relação violenta, por assimilar padrões hierárquicos de gênero considerados como "naturais", perpetuando assim, tal situação ao longo do tempo. Além disso, esta mesma mulher pode estar envolvida muitas vezes, por diferentes relações de dependência no âmbito doméstico, como a afetiva e financeira, por exemplo, o que contribui para sua dificuldade em romper com as situações que vivencia.

A fim de dar conta da complexidade que envolve esta temática, as ações de enfrentamento do problema devem ser capazes de envolver diversos setores visando efetivar a integralidade do atendimento às mulheres. Este princípio é o que pauta o Pacto Nacional pelo Enfrentamento à Violência contra as Mulheres e a formação das redes de enfrentamento à violência, através da articulação entre sociedade civil e governos nos seus diferentes níveis, para a consolidação das redes de atendimento (PASINATO, 2015) compostas por diferentes instituições responsáveis por atender e encaminhar mulheres em situação de violência (como os centros de assistência social, hospitais, postos de saúde, delegacias, defensoria pública, conselho tutelar e etc.). Essa nova roupagem institucional, que só se tornou possível à medida que o fenômeno ganhou visibilidade, abre possibilidades para que a perspectiva de enfrentamento e de atendimento humanizado possa perpassar pelo âmbito dos diferentes serviços públicos envolvidos.

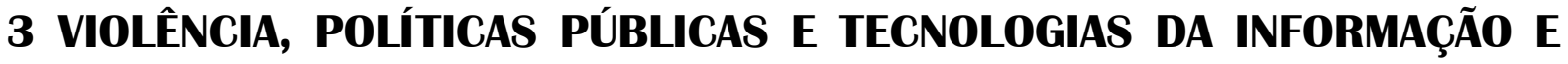 COMUNICAÇÃO (TICS)}

A violência contra as mulheres adentrou na agenda pública por meio das reivindicações históricas dos movimentos de mulheres e feministas. Hoje este fenômeno é considerado uma questão social por atingir a vida de milhões de mulheres no seu cotidiano.

Por este motivo, a perspectiva de combate à violência precisa e deve convergir para a construção de iniciativas pautadas não só em dimensões punitivas contra casos de violência, mas também no incentivo ao seu enfrentamento através de políticas públicas intersetoriais que busquem combater as diferentes formas pelas quais a violência se expressa. De acordo Política Nacional de Enfrentamento à Violência Contra as Mulheres (BRASIL, 2011), as ações devem

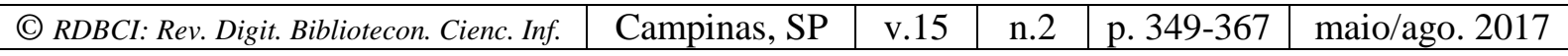


ter como intuito a construção de uma sociedade mais justa e igualitária, que busque romper os padrões culturais de desigualdade e discriminação de forma institucionalizada.

As políticas públicas voltadas para o enfrentamento da violência contra as mulheres são importantes no sentido de potencializar as transformações sociais, garantindo a efetividade de direitos e maior equidade entre cidadãs e cidadãos. É importante a percepção de que seu viés é, sobretudo, reparador e emancipatório, no sentido de que são constituídas com o intuito de combater a violência e contribuir para o minoramento das diferenças sociais existentes entre homens e mulheres. Tais políticas devem dar visibilidade às questões acima retratadas e expressar o devido reconhecimento de direitos até então suprimidos.

A trajetória dos movimentos de mulheres e feministas por meio de uma atuação no âmbito da sociedade civil como também em interação com o Estado vêm promovendo a consolidação de mudanças substantivas nas diversas áreas que perpassam a vida das mulheres, possibilitando que o tema da violência tenha cada vez mais visibilidade. Entretanto, é primordial que o tema também esteja presente em estatísticas sistemáticas e oficiais que apontem de alguma forma proporções do fenômeno (BRASIL, 2011) e sirvam de indicadores que subsidiem o planejamento e implementação de ações de enfrentamento.

Nesse sentido, compreende-se a importância e contribuição do uso das Tecnologias da Informação e Comunicação (TICs) na administração pública, ao fornecerem subsídios às capacidades administrativas do Estado para operar com cenários complexos e arranjos institucionais mais engajados no enfrentamento da violência contra as mulheres.

Dentre as várias funcionalidades advindas dos avanços tecnológicos, no que tange às políticas públicas de modo geral, o uso dos sistemas de informação tem como objetivo facilitar o desenvolvimento de redes de informações e ambientes de interação internos presentes entre governo/governo, além de ambientes externos como governo/sociedade ou governo/stakeholders. A implantação de mecanismos de tecnologia da informação viabiliza o alicerce necessário para a ocorrência de mudanças nas esferas sociais, uma vez que permite à administração pública uma acumulação de informações em diferentes setores e sobre diferentes fenômenos, possibilitando a criação de uma base de auxílio ao processo de formulação de decisões e aprimoramento dos serviços públicos.

Balbe (2010) citando Gil Garcia e Luna Reyes (2008) esclarece que as tecnologias de informação e comunicação fornecem um novo paradigma para a administração pública, indicando à magnitude das TICs a serviço do Estado. Dentre as inovações no seu uso no âmbito do "governo eletrônico" brasileiro, os autores mencionam, por exemplo, a tecnologia de banco de dados e a tecnologia de suporte à decisão, que buscam potencializar as ações governamentais.

Para situar a gestão do conhecimento e sua instrumentalização através das TICs no âmbito da administração pública, Schlesinger (2008) argumenta que é possível identificar duas

\begin{tabular}{l|l|l|l|l|l}
\hline (C) RDBCI: Rev. Digit. Bibliotecon. Cienc. Inf. & Campinas, SP & v.15 & n.2 & p. 349-367 & maio/ago. 2017 \\
\hline
\end{tabular}


áreas onde as tecnologias tornam-se imprescindíveis, a Gestão Governamental e a Gestão Organizacional, uma gestão relacionada aos programas de governo e demandas da sociedade, e a outra ao gerenciamento dos recursos disponíveis da organização, ou seja, recursos humanos, financeiros, tecnológicos e outros, respectivamente. Considerando a Política Nacional de Enfrentamento à Violência contra as Mulheres, os dois tipos de Gestão preconizados por Schlesinger (2008) podem ser visualizados: (1) Gestão Governamental como uma política pública macrossocial, onde o seu acionamento surge diante de uma demanda da sociedade, no caso aqui relatado pode ser considerada a vocalização de direitos na busca por políticas que visem à promoção dos direitos das mulheres; e (2) a Gestão Organizacional, que opera no sentido de se criar a estrutura necessária para o atendimento das demandas.

A conjugação dos dois tipos de Gestão pode ser exemplificada ao citarmos algumas das principais fontes de informação e produção de dados existentes atualmente sobre o fenômeno aqui estudado, como o Sistema Nacional de Estatísticas de Segurança Pública e Justiça Criminal/SINESPJC, sob responsabilidade da Secretaria Nacional de Segurança Pública do Ministério da Justiça; a Central de Atendimento à Mulher- Ligue 180 da Secretaria de Política para as Mulheres e o Sistema de Notificação Compulsória dos Casos de Violência contra a Mulher, sob responsabilidade do Ministério da Saúde. Este último constitui-se como o elemento a partir do qual elaboramos nossa reflexão para este trabalho.

\section{O CAMPO DA SAÚDE E A VIOLÊNCIA CONTRA A MULHER}

Para Minayo (2007), a violência é um fenômeno histórico e social, não sendo em si, uma questão de saúde pública. Entretanto, ela se transforma em um problema para este campo por justamente afetar a saúde individual e coletiva, necessitando desta forma, de ações, políticas e práticas de prevenção e enfrentamento.

Reconhecendo as várias formas de violência como um grave problema no Brasil, o Ministério da Saúde elaborou a Política de Redução de Morbimortalidade por Acidentes e Violência em 2001, e em 2003 a Política Nacional de Atenção às Urgências com diretrizes para o enfrentamento das causas externas e o aprimoramento dos atendimentos de vítimas de acidentes e violências.

A notificação relativa à violência foi estabelecida como obrigatória em todo o território brasileiro por vários atos normativos e legais, dentre eles, a notificação compulsória de violência contra a mulher através da Lei $n^{\circ}$ 10.778/2003, o Decreto $n^{\circ}$ 5.099/2004 que regulamentou este tipo específico de notificação e que atribui ao Ministério da Saúde a coordenação do plano estratégico de ação para a instalação dos serviços e instrumentos necessários, e a Portaria $n^{\circ}$ 2.406/2004 que instituiu o serviço de notificação compulsória de violência contra a mulher, aprovando os instrumentos e fluxo para notificação (BRASIL, 2009). Segundo Okabe et al.(2009), este foi o primeiro sistema de informação em saúde que

\begin{tabular}{l|l|l|l|l|l} 
(C) RDBCI: Rev. Digit. Bibliotecon. Cienc. Inf. & Campinas, SP & v.15 & n.2 & p. 349-367 & maio/ago. 2017 \\
\hline
\end{tabular} [356] 
abordou especificamente, na sua origem, a área de violência e de gênero, mesmo que não tivesse inicialmente a finalidade de dar respostas a estas questões.

O Sistema de Informações de Agravos de Notificação (SINAN) possui como principal função a realização de registros e processamento de dados relacionados à notificação de diferentes doenças e agravos à saúde de uma maneira geral em todo o território nacional ${ }^{2}$, em que a violência contra a mulher se apresenta como um dos tipos específicos de notificação. Este sistema fornece informações para a análise do perfil da morbidade e contribui para tomada de decisões dos gestores dos diferentes níveis de governo ${ }^{3}$. Quando são reunidas de forma sistematizada, estas notificações permitem o acompanhamento das características dos eventos que chegam ao sistema de saúde e, de maneira mais abrangente, possibilita a construção de modelos de análises estatísticas referentes à sua distribuição e possíveis trajetórias e tendências (CAETANO, 2009).

A ideia por trás do sistema, segundo Caetano (2009) é a busca pela correção das falhas deixadas pelo sistema anteriormente vigente, como os problemas de subnotificações, limitação das necessidades mínimas de morbidade do país, a inércia dos governos locais (municipais) em relação ao acesso ao sistema e a presença de vários outros sistemas paralelos que contribuíam para a fragmentação institucional, ou seja, cada ente da federação (estados) possuía sua própria base de dados e seus próprios padrões, transferidos quando consolidados, para o Ministério da Saúde. Atualmente, em gerência do Ministério da Saúde e das Secretarias de Vigilância à Saúde, apesar de implementado de forma heterogênea nas unidades federativas, o SINAN mostrou-se inovador no mapeamento de dados sobre agravos de notificação em todo território nacional.

De modo geral, o processo é iniciado a partir do preenchimento de um formulário/ficha individual de notificações que contém solicitações de dados gerais do paciente e, posteriormente, esta ficha é encaminhada para os setores responsáveis. Conforme portaria $\mathrm{n}^{\circ}$ 1.271, de 6 de Junho de 2014 do Ministério da Saúde, que define a lista nacional de notificação compulsória de doenças, agravos e eventos de saúde pública nos serviços de saúde públicos e privados em todo o território nacional, a notificação de tentativas de suicídio ou agressões como a violência doméstica e sexual, são realizadas através da Ficha de Notificação Individual de Violência Interpessoal/ Autoprovocada, que por sua vez está incluída na relação de doenças e agravos registrados no SINAN. Essa ficha possibilita não só registros internos dos atendimentos realizados, como também um diagnóstico e uma base de dados sobre o tipo e a quantidade de casos sobre violência contra as mulheres que chegam ao sistema de saúde, além

\footnotetext{
2 Dentre suas funções destaca-se (1) realizar o diagnóstico dinâmico da ocorrência de um evento na população; (2) monitorar a saúde da população e prever a ocorrência de eventos; (3) fornecer subsídios para explicações causais, além de vir a indicar riscos aos quais as pessoas estão sujeitas, contribuindo, assim, para a identificação da realidade epidemiológica de determinada área geográfica; e (4) auxiliar o planejamento da saúde definir prioridades de intervenção e avaliar o impacto das ações de controle desenvolvidas." (CAETANO, 2009, p.42)

${ }^{3}$ Disponível em: <http://ces.ibge.gov.br/pt/base-de-dados/metadados/ministerio-da-saude/sistema-deinformacoes-de-agravos-de-notificacao-sinan> Acesso em: 20 mar. 2016.
}

\begin{tabular}{|c|c|c|c|c|c|}
\hline (C) RDBCI: Rev. Digit. Bibliotecon. Cienc. Inf. & Campinas, SP & $\mathrm{v} .15$ & n. 2 & p. $349-367$ & maio/ago. 2017 \\
\hline
\end{tabular}


de possibilitar análises comparativas entre as diferentes regiões e municípios do país. A ficha de notificação deve ser preenchida pelos profissionais de saúde que realizem os atendimentos ${ }^{4}$ e tem caráter sigiloso. Nela há a classificação dos diferentes tipos de violência como lesão autoprovocada, violência física, psicológica/moral, tortura, violência sexual, negligência/abandono, tráfico de seres humanos, violência financeira/econômica e outras.

As diretrizes normativas que incluíram esta relação de tipos de violência no âmbito das notificações são orientadas pelo fato de que as violências contra as mulheres se constituem como um problema de alta complexidade e de pouca visibilidade social, em que o registro de tais casos nos serviços de saúde permitiria dimensionar parte da proporção do problema na sociedade, a caracterização das circunstâncias da violência e de seus envolvidos, contribuindo assim com a produção de dados e informações para o desenvolvimento de políticas e ações governamentais de enfrentamento ${ }^{5}$.

A importância da inserção deste tema no campo da saúde, segundo Schraiber e D’Oliveira (1999) é evidenciada nas correlações entre as violências em gênero e a existência de maiores riscos de agravos à saúde física e mental, além das frequências em relação ao uso dos serviços de saúde por parte das mulheres. Essas constatações são apresentadas por Schraiber et al. (2000), ao refletir sobre o número de mulheres em situação de violência que fazem uso expressivo dos serviços de saúde como uma porta de entrada, perpassando inclusive à aspectos ligados aos altos índices de sofrimento psíquico em geral, tentativas de suicídio, taxas de gravidez indesejada e aborto, além de atendimentos realizados devido a consequências de situações de violência física e/ou sexual não contabilizados nos diagnósticos e registros médicos como uma questão de violência contra a mulher, demonstrando uma invisibilidade nos serviços para além do silêncio "natural" por parte da própria mulher atendida.

Minayo (1994; apud SCHRAIBER; D’OLIVEIRA, 1999), nos indica que a inserção da violência contra as mulheres na área de Saúde Pública muitas vezes não é caracterizada como tal devido ao fato da violência ser "imperceptível", ou seja, estar enraizada na própria sociedade que, baseada nas relações de poder, tende a perpetuar de forma desigual a apropriação de bens e informações, o que acarretaria a formação de uma "rede menos aparente de violência, já que seriam 'visíveis' apenas episódios mais agudos, como a violência física explícita" (SCHRAIBER ; D’OLIVEIRA:1999:12). Nesse sentido, vem sendo realizados esforços para que os serviços de saúde tornem-se mais preparados e conscientes em relação a este tipo específico de violência através das demandas e dos atendimentos realizados.

\footnotetext{
${ }^{4} \mathrm{O}$ preenchimento de fichas de notificação e alimentação do sistema deve ser feita semanalmente. A Portaria $\mathrm{n}^{\circ}$ 1.378/GM/MS de 2013, estabelece diretrizes nacionais para a vigilância em saúde e estabelece que a manutenção dos repasses do Componente de Vigilância da Saúde está condicionada à alimentação regular do Sistema de Informação de Agravos de Notificação (Sinan), do Sistema de Informações de Nascidos Vivos (Sinasc) e Sistema de Informações sobre Mortalidade (SIM), conforme regulamentações específicas.
}

${ }^{5}$ Portaria n ${ }^{\circ} 2.406$ de 05 de novembro de 2004.

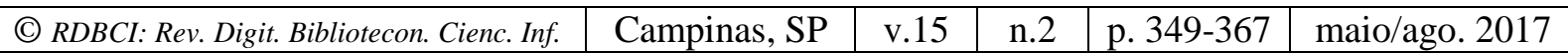


É primordial, entretanto, que os profissionais responsáveis pelos atendimentos reconheçam a violência contra a mulher como uma questão relevante, fato que evitaria posturas resistentes ou indiferentes às situações de violência. A valorização do social no campo da saúde, tradicionalmente marcado por modelos pragmáticos pautados por uma racionalidade técnico-científica, vem se dando a partir dos anos 70, ao apropriar-se de referências das ciências sociais e humanas na composição das perspectivas epidemiológicas (SCHRAIBER et al., 2009), mas que ainda nos dias atuais encontra resistências para a incorporação da temática. Para Minayo (2007), os maiores entraves se ancoram nas dificuldades do setor da saúde em aceitar na sua própria dinâmica, os problemas complexos cujo teor explicita questões da vida social e não apenas doenças de maneira geral.

Diante do papel importante desempenhado por aqueles profissionais da informação que atuam como mediadores na tramitação das notificações, Caetano (2009) citando Waldman (1998) sinalizou que existem problemas por uma grande parte dos agentes no que se refere à inserção das informações no SINAN, mais ainda quando existe uma "heterogeneidade agregada" de grupos e fatores de riscos, ou seja, erros frequentemente observados em subnotificações perante casos de maior gravidade e frequência, além de casos em que a mídia e outros meios de comunicação dão maior destaque. Dessa forma, embora as fichas de notificações sejam desenvolvidas e padronizadas para determinado fim, elas acabam de forma implícita, reproduzindo o que se considera socialmente como o mais importante. Este é o caso da violência contra a mulher, definitivamente, em que o silêncio e sua banalização ainda se constituem como os principais cúmplices das questões que envolvem as diferenciações de poder das relações de gênero.

Ainda que não exista uma mensuração em relação à qualidade do preenchimento e tramitação dos processos de notificação através dos dados disponibilizados no SINAN, alguns estudos empíricos (MENEZES et al., 2014; SCHRAIBER, et al., 2007; SALIBA et al., 2007; MELO et al., 2013; KIND et al., 2013; CORTES et al.,2015) demonstram claramente a possibilidade de considerarmos que os agentes responsáveis pelo atendimento das mulheres em situação de violência na área de saúde, em muitos casos, acabam por inserir sua percepção valorativa no preenchimento das ocorrências, arraigada de crenças, sentidos e significados atribuídos à violência contra a mulher, relacionados culturalmente à desigualdade de gênero, implicando assim, na subenumeração dos dados disponíveis. Essa mediação, segundo Cortes et al.(2015), reporta a uma situação na qual a interferência do agente público, dentro do processo de transformação da informação, apropria-se da informação e, através de seu background - valores culturais, visões ideológicas, interesses, status econômico -, produz escolhas, novos conhecimentos e, consequentemente, valores e perspectivas para seus objetos.

As barreiras culturais existentes constituem uma base simbólica e material de desafios de ordem prática, que podem explicar os descompassos entre as intenções políticas e a realidade

\begin{tabular}{l|l|l|l|l|l}
\hline (C) RDBCI: Rev. Digit. Bibliotecon. Cienc. Inf. & Campinas, SP & v.15 & n.2 & p. 349-367 & maio/ago. 2017 \\
\hline
\end{tabular}


cotidiana do agir profissional concreto (KISS; SCHRAIBER, 2011). É certo que este tema ao tomar a violência como objeto, mobiliza o emocional/afetivo nos relatos e na escuta, mas é preciso enfatizar o esforço necessário de desconstrução dos comportamentos e visões acerca da violência contra a mulher, culturalmente construídos. Para Schraiber et al. (2009), tal postura suscita a cultura capaz de exteriorizar da técnica, o social, o gênero e a subjetividade, em que situar o agir profissional no compromisso com os direitos humanos e das mulheres e, na busca de uma maior equidade de gênero, se constitui como um dos maiores desafios no campo da saúde.

Cabe observar que não só na área da saúde, mas em todos os outros âmbitos institucionais, as mudanças culturais, educativas e sociais para o enfrentamento da violência contra as mulheres se constituem como um grande desafio devido aos significados e sentidos atribuídos a ela culturalmente. Significado e sentido são entendidos aqui nos termos de Melo et al. (2013) que os consideram respectivamente como representação simbólica produzida culturalmente sobre a realidade, compartilhada socialmente por um grupo, e a forma como o sujeito opera a representação ou significado na sua práxis individual. Por esta perspectiva, o profissional responsável pelas notificações se constitui como um sujeito social e político. A notificação é um instrumento que assume diferentes significados conforme quem o preenche (se for de fato preenchido), o lugar social que o sujeito ocupa e o nível de comprometimento que ele terá com seus desdobramentos (MELO et al., 2013).

Para se buscar a igualdade entre homens e mulheres é preciso modificar os papéis tradicionalmente atribuídos para ambos na sociedade, assim como a percepção e significados que as pessoas constroem acerca destas diferenciações, buscando transformações culturais e políticas no sentido de garantir os direitos das mulheres a uma vida sem violência. Essa mudança é complexa e processual, pois deve adentrar em todos os âmbitos da sociedade com a premissa de envolver uma conscientização individual.

Percebendo a importância e relevância de que as questões de gênero estejam inseridas nas políticas públicas, os profissionais dos serviços de atendimento assumem um papel preponderante diante das circunstâncias aqui retratadas, pois a sua atuação e responsabilidade não se reduz a uma questão técnica, configurando-se também como uma prática social importante para o combate da desigualdade de gênero e efetivação dos direitos das mulheres. Nesse sentido, evidencia-se também a importância do papel do profissional da informação responsável pela alimentação dos sistemas, que atua como um mediador do processo de conhecimento sobre o fenômeno da violência (CORTES et al., 2015).

Considerando a atuação qualificada destes profissionais é possível refletir como as TICs podem se constituir como uma possibilidade na construção de indicadores ao enfrentamento da violência contra as mulheres, pois, em certa medida, são ferramentas passíveis de revelar um pouco da invisibilidade da questão ainda presente mesmo em casos aparentes de violência física.

\begin{tabular}{l|l|l|l|l|l}
\hline (C) RDBCI: Rev. Digit. Bibliotecon. Cienc. Inf. & Campinas, SP & v.15 & n.2 & p. 349-367 & maio/ago. 2017 \\
\hline
\end{tabular} 
Utilizamos como uma base para análise o Sistema de Notificação Compulsória dos Casos de Violência contra a Mulher no âmbito do SINAN. Buscamos exemplificar de forma breve e geral que, este sistema é uma ferramenta que proporciona ganhos de escala em relação à quantidade de dados sobre a violência. Entretanto, possui um contraponto, isto é, quando não alimentado de forma consciente, não garante da forma como poderia, a ruptura com a invisibilidade dos casos atendidos e contribui para a permanência do legado discriminatório que atravessa relações baseadas nos diferentes tipos de violência contra as mulheres.

Nesse sentido, os dados quantitativos obtidos no sistema informacional do Ministério da Saúde - SINAN -, podem reafirmar a invisibilidade deste tipo específico de violência, o que pode ser relacionado, principalmente, diante do que foi aqui exposto e dos estudos empíricos já citados, aos significados e sentidos que os profissionais detêm sobre o tema e sua dificuldade em lidar com as questões que possam romper com as desigualdades de gênero, advindos de uma construção sociocultural. Tal possibilidade vem mostrando ainda, a necessidade de transformações paradigmáticas (KISS; SCHRAIBER, 2011) frente à inclusão de temáticas sociais no campo da saúde, a partir de uma redefinição cultural da ação dos profissionais envolvidos, com o desenvolvimento de um olhar mais sensível e informado sobre a questão.

A título de exemplo, podemos verificar os dados disponíveis no SINAN sobre o município de Viçosa, Minas Gerais disponíveis na Tabela 1:

Tabela 1. Violência doméstica, sexual e/ou outras violências.

\begin{tabular}{lccccccc}
\hline Município de notificação & 2009 & 2010 & 2011 & 2012 & 2013 & 2014 & Total \\
\hline Viçosa & 21 & 172 & 898 & 609 & 582 & 127 & 2.409 \\
\hline
\end{tabular}

Fonte: [Ministério da Saúde/SVS - Sinan Net. Dados de 2015. Adaptado]

No ano de 2009, a população da cidade de Viçosa contava com 75 mil habitantes e 21 casos notificados de violência contra a mulher. Para o ano de 2011 este número subiu e atingiu 898 notificados, seguindo até 2014 com maiores incidências do fenômeno. Estes números observados na tabela coincidem com o processo de articulação de uma rede de proteção à mulher na cidade, por iniciativa do Conselho Municipal dos Direitos da Mulher e com a posterior inauguração da Casa das Mulheres (SANTOS, 2013), uma rede não especializada de acolhimento e encaminhamento de mulheres em situação de violência de Viçosa e região, que envolve um conjunto articulado de ações entre diferentes instituições responsáveis por atendimentos jurídicos, de assistência social, segurança pública, bem como pelos serviços de saúde.

A Casa das Mulheres realiza uma interlocução e capacitações com responsáveis pelos atendimentos nos serviços de saúde, como as unidades do Programa Saúde da Família e agentes comunitárias de saúde, acerca deste tipo específico de violência, dos desafios para seu

\begin{tabular}{l|l|l|l|l|l}
\hline (C) RDBCI: Rev. Digit. Bibliotecon. Cienc. Inf. & Campinas, SP & v.15 & n.2 & p. 349-367 & maio/ago. 2017 \\
\hline
\end{tabular}


enfrentamento e principalmente da importância do preenchimento das fichas de notificações no âmbito do SINAN, perpassando não só por conhecimentos técnicos e teóricos, como também pelas dimensões subjetivas produzidas e refletidas nos cotidianos de trabalho. Observa-se que este processo de sensibilização e formação, tem permitido a problematização das práticas profissionais e se mostrado relevante para a apropriação do tema pelas instituições e no atendimento às mulheres que se encontram em situação de violência do município, refletindo de maneira significativa nos números de notificações do município acerca da violência observados no sistema informatizado do Ministério da Saúde.

\section{CONSIDERAÇÕES FINAIS}

É inquestionável a importância da compreensão da existência de padrões hierárquicos de gênero que legitimam as desigualdades entre homens e mulheres e da necessidade de que a violência contra as mulheres ganhe visibilidade a fim de fundamentar intervenções para a mudança (OKABE; FONSECA, 2009).

Buscou-se demonstrar a relevância das estatísticas sistemáticas e informações oficiais na cobertura de casos de violência contra mulheres para que possam ter visibilidade, bem como alguns percalços que podem ser encontrados. A implementação destes sistemas pode não só propiciar a formulação de novos indicadores, como subsidiar e aprimorar o planejamento de ações para o enfrentamento da violência contra as mulheres.

Entretanto, é preciso considerar fundamentalmente o peso do caráter cultural e político que o fenômeno da violência ainda assume na sociedade atual e a forma como impacta no processo de produção da informação. Em um trabalho com perspectiva semelhante, que analisa a produção da informação em declarações de óbito pelo Sistema de Informações sobre Mortalidade (SIM), Melo et al. (2013) afirmam que o preenchimento adequado da notificação permite a construção de indicadores de saúde confiáveis a partir dos dados de violência, mas o desafio que se sobressai para o aprimoramento da qualidade da informação envolve, além de outras questões, a compreensão das dimensões subjetivas e o lugar social do sujeito responsável pelos procedimentos de preenchimento das fichas e alimentação dos sistemas.

Considerando as informações como fontes de saber e de poder, assim como Cortes et al. (2015, p.17), compreende-se que são produções seletivas, que reforçam interesses e vieses carregados de valores socialmente construídos. Nesse caso, a informação pode conduzir a uma perspectiva que não se direcione a igualdade de gênero e à justiça social, como pode também, por outro lado, "potencializar as resistências frente as mais distintas desigualdades". Nesse último sentido, a informação produzida pode, sem dúvidas, alterar relações de poder e gerar conhecimentos úteis para estimular pesquisas e estratégias de políticas públicas que propiciem mudanças no âmbito social, político e cultural no que se refere aos direitos das mulheres.

Destaca-se assim, que o poder público deve se voltar à importância e à função do uso da tecnologia e dos sistemas de informação na administração pública, bem como na produção de

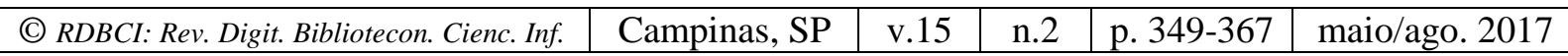


estatísticas e indicadores relacionados à violência contra as mulheres, mas enfatiza-se principalmente, a importância de que a atenção se volte para as práticas cotidianas e os processos de trabalho em que se manifesta a subjetividade dos sujeitos responsáveis pela produção de informação. Subjetividade esta atrelada a um regime de informação maior, influenciada por valores, crenças, experiências, significados e sentidos atribuídos à violência contra as mulheres, arraigados e instituídos culturalmente na sociedade, que refletem na percepção, nos procedimentos de preenchimento das fichas e no compromisso dos profissionais com os propósitos estabelecidos pelos serviços prestados.

Para o enfrentamento deste fenômeno é preciso que haja a desconstrução de visões historicamente construídas acerca do papel da mulher na sociedade, a ressignificação de valores que visem mudanças coletivas de posturas e o compartilhamento de princípios que enfatizem a promoção dos direitos das mulheres, a busca de equidade de gênero e a construção da igualdade. Para Cortes et al.(2015) a informação permeia e constitui a prática social, criando ou informando novos contextos e significados sobre os fenômenos, podendo ser vista não reduzida à uma questão técnica, mas como um elemento essencial para a desconstrução das desigualdades de gênero, para o enfrentamento da violência e efetivação dos direitos das mulheres.

É preciso asseverar nesse sentido, a importância de que esta perspectiva esteja presente em todos os âmbitos sociais e concernentes à administração pública. Pautar questões de gênero e atuar no enfrentamento da violência contra as mulheres não é algo circunscrito a um único órgão ou setor. Saliba et al. (2007) demonstram que não cabe apenas ao setor de saúde assumir a responsabilidade no enfrentamento à violência, entretanto, tem o dever legal e ético de envolvimento institucional, de modo a capacitar seus profissionais para o diagnóstico das situações de violência e sobre a importância da questão. Esta atenção se pauta principalmente por ser um setor que possui a tradição da prevenção e do cuidado (MINAYO, 2007), demonstrando que a integração intersetorial (SCHRAIBER; D'OLIVEIRA, 1999) e apoio de todos os setores na redução das desigualdades de gênero é um fator primordial e se constitui como um desafio na incorporação do enfoque destas questões por políticas públicas (FARAH, 2004).

No que se refere especificamente ao preenchimento das notificações acerca dos eventos de violência contra as mulheres no campo da saúde pública, Melo et al. (2013) apontam alguns fatores determinantes para a melhoria da informação obtida, perpassando pela importante e necessária capacitação e sensibilização dos codificadores visando o aperfeiçoamento do preenchimento das fichas e a busca ativa de informações sobre os eventos também em outras fontes, como por exemplo, as delegacias de polícia. A busca ativa se faz necessária no contexto atual devido à desintegração dos dados acerca da violência nos diferentes sistemas de informação que abordam tal questão, em que a tecnologia disposta ainda não se mostra intercambiável e passível de trocas. Okabe e Fonseca (2009) mostram que a consolidação dos dados e informações é também um dos desafios a serem superados com vistas ao 
monitoramento da violência contra as mulheres, pressupondo a existência de uma política de informação que transite não apenas por questões de gênero e violência, mas de articulação intra e intersetorial. Entretanto, considera-se que as ações intersetoriais só terão também maior eficácia se realizadas com base em informações confiáveis produzidas e compartilhadas pelos diversos atores sociais envolvidos (CORTES et al., 2015, p.18).

\section{REFERÊNCIAS}

BALBE, Ronald da Silva. Uso de tecnologias de informação e comunicação na gestão pública: exemplos no governo federal. Revista do Serviço Público. Brasília, 61, 2, p.189209, jun, 2010. Disponível em: 〈http://repositorio.enap.gov.br/handle/1/1613 >. Acesso em: 18 mai. 2016.

BRASIL. Decreto no 5.099, de 3 de junho de 2004. Regulamenta a Lei no 10.778, de 24 de novembro de 2003, e institui os serviços de referência sentinela. Diário Oficial da União, Poder Executivo, Brasília, DF, p.3, 4 jun. 2004.

BRASIL. Lei no 10.778 , de 24 de novembro de 2003. Estabelece a notificação compulsória, no território nacional, do caso de violência contra a mulher que for atendida em serviços de saúde públicos ou privados. Diário Oficial da União, Poder Executivo, Brasília, DF, p. 11, 25 nov. 2003.

BRASIL. Ministério da Saúde. Secretaria de Vigilância à Saúde. Instrutivo de preenchimento da ficha de notificação: investigação de violência doméstica, sexual e/ou outras violências. Brasília: SINAN NET; DASIS/CGDANT, 2009. Disponível em: <http://www.pmf.sc.gov.br/arquivos/arquivos/pdf/30_03_2012_8.40.46.6cb50967bbeb1 8008432b71da11ac636.pdf $>$. Acesso em: 18 mai. 2016.

BRASIL. Presidência da República. Secretaria de Políticas para as Mulheres. Política nacional de enfrentamento à violência contra as mulheres. Brasília: Presidência da República/SPM, 2011. Disponível em: 〈http://www.spm.gov.br/sobre/publicacoes/ publicacoes/2011/politica-nacional > . Acesso em 18 mai. 2016.

CAETANO, Rosângela. Sistema de Informação de Agravos de Notificação (SINAN). In: BRASIL. Ministério da Saúde; Organização Pan-Americana da Saúde; Fundação Oswaldo Cruz. A experiência brasileira em sistemas de informação em saúde. Brasília: Editora do Ministério da Saúde, 2009. v. 2. (Série B. Textos Básicos de Saúde).

CHOO, Chun Wei. A organização do conhecimento: como as organizações usam a informação para criar significado, construir conhecimento e tomar decisões. Trad. Eliana Rocha. São Paulo: Editora Senac, 2003.

CORTES, Gisele R.; ALVES, Edvaldo C.; SILVA,Leyde K. R. Mediação da informação e violência contra mulheres: disseminando a informação estatística no Centro Estadual de Referência da Mulher Fátima Lopes. In: ENCONTRO NACIONAL DE PESQUISA EM CIÊNCIA DA INFORMAÇÃO, 16.,2015, João Pessoa. Anais... João Pessoa: UFPB, 2015. 
Disponível em: <http://www.ufpb.br/evento/lti/ocs/index.php/enancib2015/enancib2015 /paper/view/3028 > Acesso em: 18 mai. 2016.

FARAH, Marta Ferreira Santos. Políticas Públicas e gênero. In: GODINHO, Tatau; SILVEIRA, Maria Lúcia da (Org.). Políticas públicas e igualdade de gênero. São Paulo: Coordenadoria Especial da Mulher, 2004.

GONZÁLEZ DE GÓMEZ,Maria Nélida. Regime de informação: construção de um conceito. Inf. \& Soc.: Est., João Pessoa, v.22, n.3, p. 43-60, set./dez. 2012. Disponível em: $<$ http://www.ies.ufpb.br/ojs/index.php/ies/article/view/14376/8576>. Acesso em: 18 maio. 2016.

HEILBORN, Maria Luiza; ARAÚJO, Leila; BARRETO, Andreia. Gestão de políticas públicas em gênero e raça (GPP GER). In: (Org.). Curso de especialização em gestão de políticas públicas com ênfase em gênero e relações etnorraciais: módulo 5. Rio de Janeiro: CEPESC; Brasília, Secretaria de Políticas para as Mulheres, 2010.

KIND, Luciana. et al. Subnotificação e (in)visibilidade da violência contra mulheres na atenção primária à saúde. Cad. Saúde Pública, Rio de Janeiro, v. 29, n. 9, p.1805-1815, set. 2013. Disponível em: 〈http://periodicos.fiocruz.br/pt-br/publicacao/15797>. Acesso em: 18 maio. 2016.

KISS, Lígia Bittencourt ; SCHRAIBER, Lilia Blima. Temas médico-sociais e a intervenção em saúde: a violência contra mulheres no discurso dos profissionais. Ciência \& Saúde Coletiva, v. 16, n. 3, p.1943-1952, 2011. Disponível em: <http://www.scielo.br/pdf/csc/v16 n3/28.pdf>. Acesso em: 18 maio. 2016.

MELO, Cristiane Magalhães. et al. Produção da informação sobre mortalidade por causas externas:sentidos e significados no preenchimento da declaração de óbito. Ciência \& Saúde Coletiva, v. 18, n. 5, p.1225 -1234, 2013. Disponível em: <http://www.scielo.br/scielo.php? script=sci_arttext\&pid=S1413-81232013000500007>. Acesso em: 18 maio. 2016.

MINAYO, Maria Cecília de Souza. A inclusão da violência na agenda da saúde: trajetória histórica. Ciência \& Saúde Coletiva, v. 11, Sup., p. 1259-1267, 2007. Disponível em: 〈http://www.scielo.br/scielo.php?script=sci_arttext\&pid=S1413-81232006000500015>. Acesso em: 18 maio. 2016.

MENEZES, Paulo Ricardo de Macedo. et al. Enfrentamento da violência contra a mulher: articulação intersetorial e atenção integral. Saúde Soc. São Paulo, v.23, n.3, p.778-786, 2014. Disponível em: 〈http://www.revistas.usp.br/sausoc/article/view/88565/91446>. Acesso em: 18 maio. 2016.

OKABE, Irene; FONSECA, Rosa Maria Godoy Serpa da. Violência contra a mulher: contribuições e limitações do sistema de informação. Rev. Esc. Enferm. USP, São Paulo, v.43, n.2 , jun. 2009. Disponível em: $\lfloor$ http://www.scielo.br/scielo.php?script=sci arttext\&pid=S0080-62342009000200027>. Acesso em: 18 maio. 2016. 
PASINATO, Wânia. Oito anos de Lei Maria da Penha. Entre avanços, obstáculos e desafios. Estudos Feministas, Florianópolis, v. 23, n. 2, p. 533-545, maio/ago. 2015. Disponível em: <http://www.scielo.br/scielo.php?script=sci_arttext\&pid=S0104026X2015000200533>. Acesso em: 18 maio. 2016.

SALIBA, Orlando. et al. Responsabilidade do profissional de saúde sobre a notificação de casos de violência doméstica. Rev. Saúde Pública, v. 41, n. 3, p. 472-477, 2007. Disponível em: <http://www.scielo.br/scielo.php?script=sci_arttext\&pid=S003489102007000300021>. Acesso em: 18 maio. 2016.

SANTOS, Ana Pereira dos. Projeto "Casa das Mulheres": o desafio do enfrentamento à violência doméstica em redes não-especializadas. In: SEMINÁRIO INTERNACIONAL FAZENDO GÊNERO, 1., 2013, Florianópolis. Anais eletrônicos... Florianópolis: UFSC, 2013. Disponível em: < http://www.fg2013.wwc2017.eventos.dype.com.br/resources/ anais/20/1373488138_ARQUIVO_TextocompletoFazendoGenero.pdf > Acesso em: 18 maio. 2016.

SCHLESINGER, Cristina Costa Barros. et al. Gestão do conhecimento na administração pública. Curitiba: Instituto Municipal de Administração Pública - IMAP, 2008. Disponível em: 〈http://www.imap.curitiba.pr.gov.br/wp-content/uploads/Acervo/Publicacoes_Imap /Livros/2008_0001_Gestao_Conhecimento_Adm_Pub.pdf >. Acesso em: 18 mai. 2016.

SCHRAIBER, Lilia Blima. et al. A violência contra mulher: demandas espontâneas e busca ativa em unidade básica de saúde. Saúde e Sociedade, v. 9, n. 1/2, p. 3-15, 2000. Disponível em: <http://www.scielo.br/scielo.php?script=sci_arttext\&pid=S0104-12902000000100002 >. Acesso em: 18 maio. 2016.

SCHRAIBER, Lilia Blima. et al. Violência contra mulheres entre usuárias de serviços públicos de saúde da Grande São Paulo. Rev Saúde Pública, v. 41, n.3, p. 59-67, 2007. Disponível em: 〈http://www.redalyc.org/articulo.oa?id=67240160006 > Acesso em: 18 maio. 2016.

SCHRAIBER, Lilia Blima; D'OLIVEIRA, Ana Flávia Pires Lucas. Violência contra as mulheres: interfaces com a saúde. Interface_Comunicação, Saúde, Educação, v.3, n.5, 1999. Disponível em: 〈http://www.scielo.br/pdf/icse/v3n5/03.pdf >. Acesso em: 18 maio. 2016.

SCHRAIBER, Lilia Blima. et al. Violência de gênero no campo da Saúde Coletiva: conquistas e desafios. Ciência \& Saúde Coletiva, v. 14, n.4, p. 1019-1027, 2009. Disponível em: 〈http://www.scielo.br/scielo.php?script=sci_arttext\&pid=S1413-81232009000400009> Acesso em: 18 maio. 2016.

SOARES, Vera. Políticas públicas para igualdade: papel do Estado e diretrizes. In: GODINHO, Tatau; SILVEIRA, Maria Lúcia da (Org.). Políticas públicas e igualdade de gênero. São Paulo: Coordenadoria Especial da Mulher, 2004. p.113-126. (Cadernos da Coordenadoria Especial da Mulher, 8). 


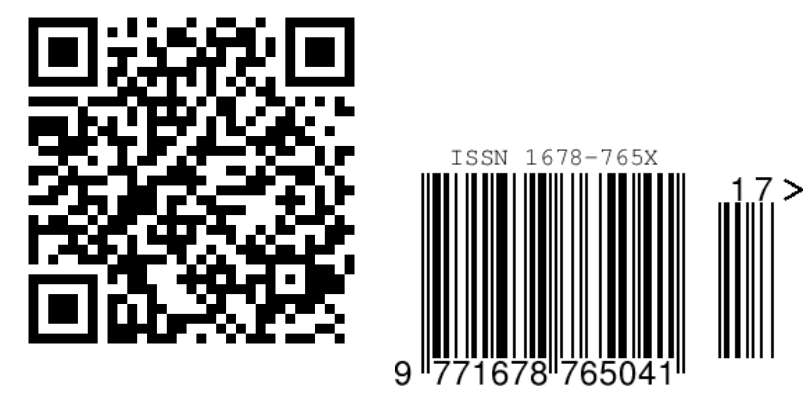

